\title{
Modalidades escolares y tendencias poblacionales en la Meseta Central de Chubut, Argentina ${ }^{1}$
}

\section{School modalities and population trends in the Meseta Central of Chubut, Argentina}

\author{
Melisa Brenda Di Paolo \\ melisadipaolo@gmail.com \\ Universidad de Buenos Aires, Argentina
}

Recepción: 03 Junio 2021

Aprobación: 17 Septiembre 2021

Publicación: 01 Noviembre 2021

Cita sugerida: Di Paolo, M.B. (2021). Modalidades escolares y tendencias poblacionales en la Meseta Central de Chubut, Argentina. Anuario del Instituto de Historia Argentina, 21(2), e147. https://doi.org/10.24215/2314257Xe147
Resumen: El presente artículo recorre los roles que ha jugado la escuela ${ }^{2}$ hasta la actualidad -incluyendo sus cambios de modalidad- en los movimientos poblacionales de la Meseta Central de Chubut, un espacio caracterizado por ser un contexto ruralizado. Así, se propone un abordaje sobre el proceso de escolarización de la zona en vinculación dialógica con sus cambios económicos y migratorios. Técnica y metodológicamente, se diferencian tres períodos del desarrollo territorial, en los que se da cuenta de cómo las dinámicas poblacionales de repoblamiento, despoblamiento y concentración estimulan y dirigen el sistema escolar en la Meseta; a la vez que estos cambios son impulsados y profundizados por las modalidades que va asumiendo la escuela en este territorio. Asimismo, el trabajo apela tanto a entrevistas en profundidad con informantes clave realizadas en los años 2016 y 2019 , como a datos de índole cuantitativa provenientes de fuentes primarias y secundarias. ${ }^{3}$

Palabras clave: Modalidades escolares, Repoblamiento, Despoblamiento, Concentración, Meseta Central de Chubut.

\begin{abstract}
This article analyzes the role the school has played in the population movements of a specific ruralized context: the Meseta Central of Chubut. Thus, a study is proposed on the Mesetense schooling process in dialogic connection with the economic and migratory changes in the area. For this, three periods of territorial development are differentiated in which it is realized how the population dynamics of repopulation, depopulation and concentration stimulate and direct the school system in the Meseta; at the same time that these changes are driven and deepened by the modalities that the school is assuming in this territory. For this, in-depth interviews conducted with key informants in 2016 and 2019 will be analyzed; as well as data of a quantitative nature from primary and secondary sources.
\end{abstract}

Keywords: School modalities, Repopulation, Depopulation, Concentration, Meseta Central of Chubut. 


\section{INTRODUCCIÓN}

El nacimiento de la escuela moderna en la Argentina se dio en sintonía con el proceso de consolidación del Estado nación. Bajo una impronta nacionalizadora y capitalista, buscó formar mano de obra a las alturas de estas nuevas exigencias. Así erigida por la Ley de Educación Común 14204(1884), la institución escolar buscó modificar las formas de vida, conocimientos y hábitos de las niñas y los niños -ahora alumnado- en tanto futuras generaciones trabajadoras argentinas bajo un ideal homogeneizador de su población.

En la ruralidad, expandir la escolaridad implicó-y aún lo hace- diversas adaptaciones institucionales tendientes a garantizar la asistencia de las y los estudiantes, sorteando dificultades climáticas y de dispersión poblacional, ambas de gran envergadura, como se verá luego. En la actualidad, luego de la Ley Nacional de Educación (2006), todas estas formas escolares adaptativas se engloban por primera vez bajo la denominada "modalidad rural".

Se ha escrito mucho acerca del carácter disciplinador y nacionalizador de la escuela moderna en general, y la argentina en particular; de su rol en la modificación y adaptación de las prácticas y hábitos para las necesidades del sistema capitalista. No obstante, este trabajo se propone comprender un cruce poco estudiado: la incidencia de la escuela en los modos y lugares de residencia de familias en contextos ruralizados; específicamente, se abordará el desarrollo de la escolaridad en la Meseta Central de Chubut (MCCh) en relación con las tendencias migratorias de esta zona. Este desarrollo da cuenta de un in crescendo en la valorización positiva de la institución escolar por parte de la población local en tanto preparación y formación de las generaciones más jóvenes para sus futuras inserciones sociales y laborales; así como de la importancia asignada al rol familiar en el acompañamiento educativo. En sintonía, se dio un cambio de enfoque estatal acerca de la función de la escuela en contextos ruralizados, que pasó de una óptica civilizatoria a una de derecho en respeto del vínculo familiar y comunitario. Ambos procesos se tradujeron en las modalidades educativas ofertadas y en la forma y el lugar de residencia de los habitantes de la MCCh.

Para esto, se propone una periodización específica que da cuenta de la relación entre las modificaciones atravesadas por las modalidades escolares ofertadas para la población de la MCCh y las dinámicas poblacionales y económicas de la zona. Se trata de un complejo de relaciones que, lejos de ser lineal, se retroalimenta y estimula en diversos sentidos.

Analíticamente, y en función de este trabajo, se historiza el desarrollo de la MCCh en tres períodos. Primero, su incorporación al Estado nacional argentino a fines del siglo XIX mediante, principalmente, la violencia física, y luego, también, simbólica. Así planteado, este proceso estuvo atravesado por la organización del repoblamiento de la zona, y fue dirigido por la llegada del ganado ovino (Troncoso y Flores Torres, 2012; Aparicio, Crovetto, Ejarque, 2013) proveniente de la región pampeana, ahora principal actividad motorizadora de este nuevo territorio nacional. En este mismo período, la instalación de la escolaridadconcebida por la clase dirigente como clave para lograr la incorporación de la población a determinados valores, saberes y prácticas nacionales- estuvo sujeta a debates en torno a la modalidad más idónea para retener y educar a la niñez residente en forma dispersa. Especial atención recibieron las familias de pueblos originarios, cuyos hábitos de vida eran entendidos como opuestos a la vida civilizada que quería instalarse. La escuela de tipo internado ${ }^{5}$ fue la forma institucional triunfante y la que, con modificaciones, aún hoy tiene vigencia para esta misma población objetivo. En vinculación con este fin de modificar hábitos mediante el funcionamiento de instituciones educativas, se promueve la fundación de Aldeas Escolares para motivar la instalación y nucleamiento poblacional, buscando favorecer el ordenamiento socio-espacial.

El segundo período estuvo marcado por la crisis de la producción ovino-lanar (Ejarque, 2014), lo que trajo aparejado el despoblamiento, envejecimiento y concentración poblacional dentro de la MCCh. Como consecuencia de esta última dinámica -pero en un proceso dialéctico-,la mayoría de las niñas y los niños que aún residen en la meseta concurren a escuelas cercanas a sus casas en los pequeños parajes rurales. En cambio, las de tipo internado comienzan a perder matrícula, cambian su nombre a albergues y reducen el tiempo que 
el alumnado pasa alejado de su familia. Con estos cambios se buscó disminuir el desarraigo del estudiantado, con miras a incidir en sus proyectos y trayectorias futuras más vinculados a sus contextos de origen.

Finalmente, en el período actual la disminución de la población mesetensese ha desacelerado, mientras que se ha profundizado la concentración en pequeños parajes y pueblos rurales; sobre todo, en un esquema de familias divididas entre madres y niños/as en los pueblos, y padres en los campos. En cuanto a la escuela, diversos cambios se suscitaron producto de la sanción de la Ley Nacional de Educación en el año 2006. Con la extensión dela obligatoriedad escolar para el nivel secundario, y el establecimiento de la modalidad rural como transversal al sistema, se crearon nuevas formas institucionales para el nivel medio, con docentes disciplinares itinerantes. Bajo la impronta de evitar el desarraigo de las y los estudiantes, y el despoblamiento y envejecimiento de la población rural, se introdujeron nuevas modificaciones en las escuelas albergue, ahora denominadas Casas y Residencias estudiantiles.

Metodológicamente, este trabajo combina entrevistas semi-estructuradas a informantes clave realizadas en 2016 y $2019,{ }^{6}$ y datos cuantitativos de fuentes primarias ${ }^{7}$ y secundarias.

En pos de simplificar la lectura del análisis hasta aquí presentado, en primer lugar se expondrá una caracterización actual y general de la MCCh. Luego se abordará la periodización antes presentada; y, por último, se concluirá con algunas reflexiones que evidencien la relación dialógica entre el cambio de las modalidades escolares y las distintas dinámicas poblacionales de la MCCh, especialmente las vinculadas a los movimientos de migración y asentamiento.

\section{Caracterización de la aCtUalidad en La MCCH}

La MCCh es un vasto territorio ubicado al centro de la provincia de Chubut, que ocupa un tercio de la dimensión total provincial (ver Figura 1). A pesar de su extensa amplitud, su población es escasa -tiene una densidad poblacional de $0,4 \mathrm{~h} / \mathrm{km}^{2}$ - y se la encuentra con frecuencia concentrada en pequeños parajes rurales. Fruto de un progresivo despoblamiento, fundamentalmente producto de un proceso migratorio hacia otros aglomerados, la meseta ha disminuido un tercio de su población desde fines de la década del 60 y está cada vez más envejecida. Esta tendencia contrasta con la dinámica provincial que, según los Censos Nacionales de Población, ha crecido más de siete veces entre 1960 y 2010. Se trata de diferencias de crecimiento que también se constatan en el proceso de urbanización: mientras la provincia ha dejado de ser demográficamente considerada rural en los 60 (Hermosilla Rivera, 2013), la meseta continúa siendo enteramente rural. ${ }^{8}$ 
FIGURA 1

Mapa de la Comarca de la Meseta Central de Chubut ${ }^{9}$

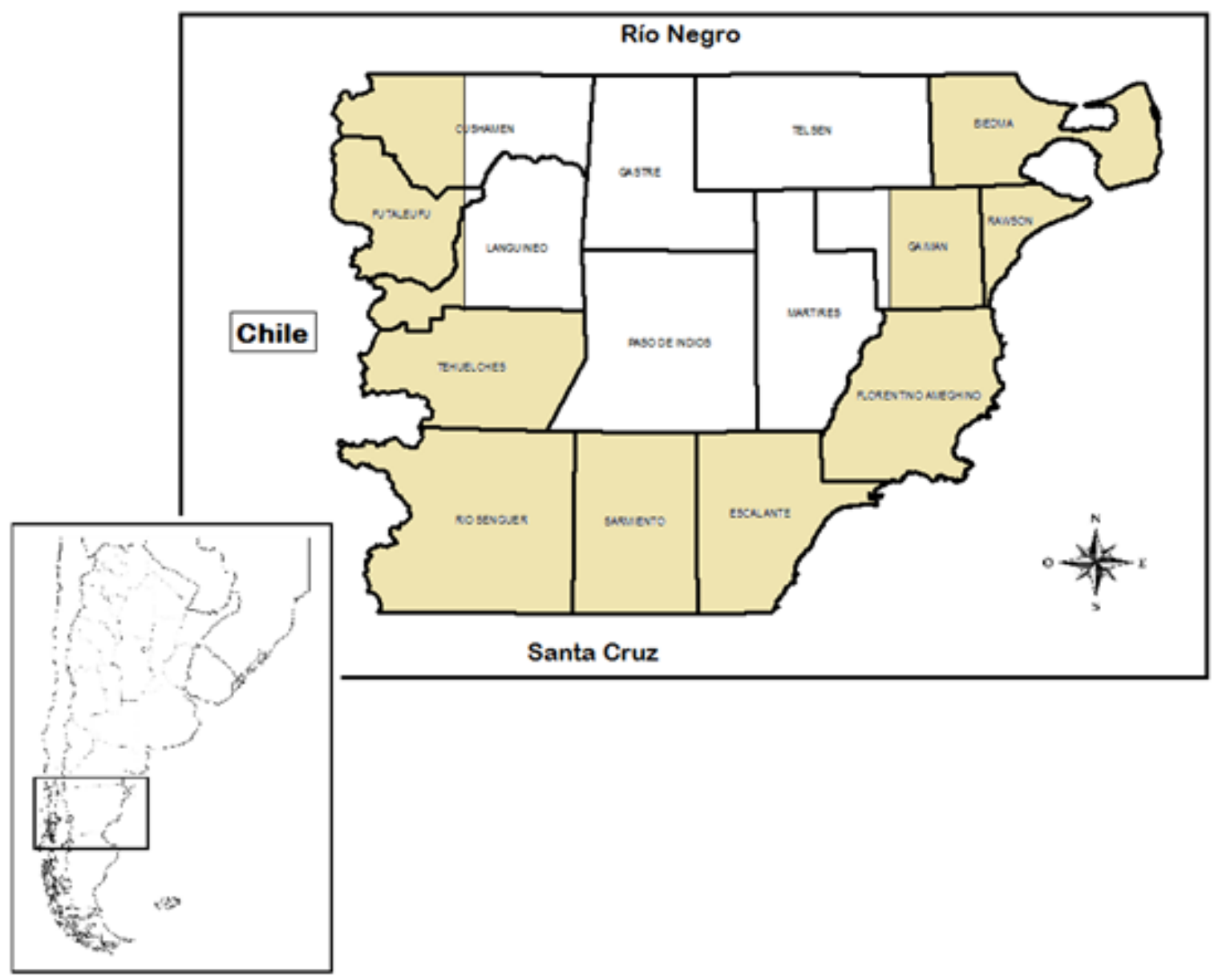

Fuente: Elaboración propia sobre la base de Subsecretaría de Regulación y Control Ambiental, Ministerio de Ambiente y Control del Desarrollo Sustentable, Chubut

La principal fuente de empleo se asocia con el Estado: el 60\% de los habitantes mesetenses son empleados públicos. Le siguen el comercio y el área de servicios, junto con el trabajo en la ganadería caprina y ovina. Dado su bajo dinamismo económico, el $62,1 \%{ }^{10}$ de la población recibe algún tipo de asistencia o subsidio estatal. Se evidencia con estos datos la centralidad económica del Estado en esta zona, principalmente en un rol asistencial (Carabelli, Demarchi y Baroli, 2008).

Dadas las características de amplitud territorial y escasez poblacional de la MCCh, el promedio de instituciones educativas y de salud por kilómetro cuadrado es mucho mayor al del promedio provincial. Respecto del acceso a servicios de salud, existen 9 puestos sanitarios y 5 hospitales rurales; ${ }^{11}$ para tratar los casos de mayor gravedad, es necesario recurrir a los centros urbanos más cercanos. En cuanto a los servicios educativos, en la MCCh se emplazan 24 escuelas de nivel primario y 7 de nivel secundario. En referencia a esta escasez histórica de instituciones educativas, la meseta tiene las tasas de analfabetismo más altas de la provincia: $10 \%$ de analfabetos entre los habitantes mayores de 10 años. ${ }^{12}$

Si profundizamos en las modalidades escolares ofertadas en la actualidad para la población mesetense, se puede diferenciar entre aquellas que se emplazan en los pueblos, tienen una jornada simple y un cuerpo docente estable; se trata de la más común para los niveles inicial y primario. Mientras que las destinadas a la educación media, si bien también tienen lugar en los pueblos, presentan una modalidad de itinerancia para las y los docentes disciplinares, que concurren a la escuela cada 15 días y dejan tareas a las y los alumnos y docentes tutores/as del curso. ${ }^{13}$ Por otro lado, están las Casas ${ }^{14}$ y Residencias estudiantiles, ${ }^{15}$ que brindan 
albergue cercano a una escuela, están destinadas a la población rural dispersa, y para todos los niveles del sistema (inicial, primario, secundario y terciario), aunque la matrícula se concentra mayormente en población adolescente y juvenil, y en los niveles educativos más avanzados.

Hasta aquí se ha descripto la fotografía actual; los próximos apartados tratarán de desandar estas características, apelando a una historización que dé cuenta del vínculo entre los cambios poblacionales de la MCCh: repoblamiento, despoblamiento y concentración, junto con las diversas formas que fue asumiendo la institución escolar.

\section{OVINIZACIÓN ${ }^{16}$ Y NACIONALIZACIÓN DE LA MCCH}

El territorio sur argentino fue incorporado a la nación a fines del siglo XIX en un proceso de construcción de hegemonía por medio de la coerción y la búsqueda de consenso, en términos gramscianos. Económicamente, el impulso estuvo dado por la necesidad de trasladar los ovinos de la región pampeana, otrora más rentables que el ganado vacuno, pero que luego de la aparición de los frigoríficos y el alza de la demanda británica de carne vacuna congelada pasaron a ser empujados hacia el sur, con lo que se liberaban las mejores tierras de la región pampeana (Giberti, 1962). Al respecto, y para el caso de la provincia del Chubut, Taraborelli sostiene:

En los años de la Argentina "granero del mundo" se impuso la imagen de la ganadería ovina como la "locomotora del desarrollo" de la provincia de Chubut. Tal es así que, desde la fractura más reformista de la oligarquía, Ramos Mexía (intelectual Ministro de Agricultura primero y de Obras Públicas después) afirmaba que "la Patagonia está destinada a ser el criadero ovino de la Argentina, y será ella el área que salvará de un completo naufragio esa fuente otrora tan exuberante de su riqueza (López, 2003, en Taraborelli, 2019, p.360).

En este proceso de legitimación nacionalizadora, se pasó de un primer momento de incorporación territorial basado fundamentalmente en la violencia física, a otro de carácter simbólico. Se entiende aquí la violencia simbólica en el sentido bourdeano del término, como el conjunto de aquellas acciones tendientes a hacer pasar una forma particular de pensar por una universal (Bourdieu, 1994; Bourdieu y Passeron, 1996; Morales Zuñiga, 2009). Se abre así un proceso de territorialidad (Sack, 1986; Haesbaert, 2013): la construcción de un nuevo territorio por medio de la instalación de determinadas relaciones de poder.

Esta territorialización estuvo atravesada por el repoblamiento de la MCCh, principalmente con familias y grupos vinculadas con pueblos originarios mapuches y tehuelches provenientes del norte patagónico y la zona pampeana, así como de Chile; y en menor medida, conformados por descendientes europeos (alemanes, españoles, vascofranceses, ingleses y siriolibaneses) (Troncoso y Flores Torres, 2012).Este proceso de poblamiento y uso de las tierras, que comenzó de un modo anárquico, luego fue ordenado estatalmente -y de forma obligada- en un sentido desigual (Troncoso y Flores Torres, 2012).Los permisos otorgados por medio de la Oficina de Tierras, o de sus inspectores, diferenciaron grandes y pequeños productores por la desigual entrega de permisos de adjudicación de venta para los primeros y de tipo precario para los segundos. Así, se acentuaron aún más las posiciones favorecedoras y desfavorecedoras de estos actores económicos (Ejarque, 2014; Taraborelli, 2019).

El ordenamiento de la población mesetense también estuvo dirigido por las necesidades comerciales de la producción ovino-lanar. Con el objeto de facilitar el acceso hacia los puertos de Trelew y Puerto Madryn, y la estación de tren de Jacobacci, se generaron precarios caminos (Troncoso, 2008). Eran trazados en cuyos puntos estratégicos fueron paulatinamente asentándose población y mercachifles ambulantes, con boliches y almacenes de ramos generales. La mayoría de los pueblos actuales de la MCCh tiene sus orígenes en este proceso.

Otro de los temas clave para el Estado en este período que hemos denominado de territorialización, y que tendió a organizar el repoblamiento, fue la instalación de distintos tipos de instituciones nacionales; sobre todo de la escuela, entendida por la élite gobernante como institución garante de la igualdad de oportunidades 
y acceso a saberes socialmente válidos; y cuyo deber era aplanar las diferencias, homogeneizando la población sin importar sus orígenes (Pierini et.al, 2009). En palabras del presidente del Consejo Nacional de Educación ${ }^{17}$ (CNE) de esa época:

La escuela en las colonias y territorios debe ser el mejor medio y más eficaz para atraer a sus pobladores a nuestras costumbres, a nuestros hábitos y hasta hacerles comprender el respeto y obediencia que deben a nuestras leyes y autoridades (Zorrilla, ${ }^{18}$ 1886, en Duarte, 2015, p.9).

En la MCCh las dificultades de escolarizar a la población estaban dadas principalmente por su carácter disperso, además de las resistencias familiares para aceptar el orden y las costumbres que les demandaba. Así, desde el CNE se analizaron, debatieron y pusieron en marcha tres tipos de modalidades: las escuelas ambulantes, las de internado y las Aldeas escolares. Las del primer tipo tuvieron la menor duración, se crearon en 1914 y dejaron de existir en 1925.Su funcionamiento constaba de escuelas "rodantes" que visitaban distintos puntos de nucleamiento poblacional, y en las que se dictaban nociones elementales de Lectura y Escritura, Aritmética, Geografía e Historia Argentina (Caviglia, 2011). Cerraron dado que, según el CNE, no lograron impartir el mínimo de valores, prácticas y formación buscada:

La ley orgánica 1420 considera la situación, y sugiere para resolverla la instalación de escuelas ambulantes. Han sido ya ensayadas infructuosamente. Representan un costo enorme y mantienen intacto el problema. Las escuelas ambulantes, domiciliarias y complementarias, los planes especiales y alimentación parcial, no modifican la naturaleza de las cosas ni afrontan la dificultad en todos sus aspectos. No pueden cambiar la distribución territorial de la población, donde cada familia separada por largas distancias necesita maestros, donde la falta absoluta de recursos mata todo anhelo y destruye todo esfuerzo (Cárcano, 1933, p.11).

Estas instituciones ambulantes fueron contrapuestas y debatidas en torno a otra alternativa: las escuelas de tipo internado. Principalmente, los argumentos a favor de ellas se basaron en la importancia de retener a los niños y niñas el mayor tiempo posible en vínculo con el mundo civilizado, y en aislamiento de las malas costumbres familiares; sobre todo, cuando estas familias provenían de pueblos originarios:

En las horas de clase podría el maestro tener sus niños en orden, vigilar todos sus actos para impedir la práctica de sus malas inclinaciones y darles el buen ejemplo. El niño, al volver a su casa, encuentra al padre tirado con indolencia o ebrio entre sus perros y gatos, que como él, buscan el descanso en las cenizas del fuego (...) Dos son los asuntos capitales que merecen especial atención para hacer compenetrar las nociones de la educación en esta clase de niños: la asistencia y el aislamiento del hogar, por el mayor tiempo que fuera posible, mientras concurran a la escuela. (Funes, citado en Caviglia, 2011, p.432)

La modalidad escolar de internado constaba de hogares contiguos a la escuela, donde el alumnado vivía durante la mayor parte del año y regresaba al hogar familiar sólo en las vacaciones de verano e invierno, aunque estas últimas solían posponerse por razones climáticas que dificultaban el traslado de familias y niños. Este tipo de instituciones aún existe como oferta educativa para la población mesetense, aunque han cambiado aspectos de su funcionamiento y respecto de su público objetivo.

En lo relativo a las Aldeas Escolares, encarnaron en la práctica las ideas que sostenían la institución escolar como estimuladora del asentamiento poblacional organizado.

Establecimientos rurales [...] vendrían a ser con el tiempo, quizá, causa generadora de villas y pueblos. Faros de luz en los desiertos, serían el refugio de los náufragos del mar de la ignorancia, y guía de los extraviados por la senda del vicio y del crimen. (Molina, citado en Caviglia, 2011, p.80)

Constaban de una escuela como centro, rodeada por viviendas construidas -o facilitadas en su construcción- por el Estado. Las y los docentes gozaban de una autoridad tácita que les permitía impartir normas de convivencia, principalmente la decisión sobre quiénes podían y quiénes no residir en las Aldeas: se excluía a los hombres adultos, incluso a los pertenecientes a las mismas familias. Además, se prohibía el consumo de bebidas alcohólicas y la realización de fiestas, por nombrar algunos ejemplos (Franco, 2003).La costumbre impulsada por este tipo de asentamientos se ha masificado en la actualidad; es muy común que las 
madres y sus hijos vivan en los pueblos -cerca de la escuela y de otras instituciones estatales y comercialesmientras que los padres residen en los campos y vuelven periódicamente al hogar familiar.

En suma, durante este período de territorialización de la MCCh la escuela cumplió un rol nacionalizador de la población recientemente incorporada; de socialización en la vida civilizada de las nuevas generaciones, separada de los malos hábitos familiares y comunitarios; y de asentamiento poblacional.

\section{Crisis DE LA PRODUCCIÓN OVINO-LANAR Y DESARRAigo}

A partir de la década de 1960 la producción ovino-lanar empieza a estancarse, para luego entrar en crisis. Las causas pueden analizarse en tres distintos niveles: internacional, nacional y local. En el plano internacional, con la aparición y difusión de los sintéticos, esta materia prima perdió importancia para el mercado textil, lo que bajó sus precios. Nacionalmente, no se había desarrollado un mercado textil donde se pudiesen colocar los productos como alternativa a la merma en las exportaciones; además, se modificó el régimen impositivo que estimulaba esta producción, sobre todo con las retenciones aplicadas durante los 60. En lo referido a lo local, se dieron distintas dificultades ambientales relativas al deterioro y agotamiento de los suelos (Ejarque, 2014).

A causa de la depresión en la principal actividad económica de la zona, muchos productores abandonaron sus campos para vivir en los incipientes pueblos mesetenses o migrar hacia otras zonas de la provincia. Fueron dos dinámicas que marcaron profundamente este período y que aún continúan en la actualidad, aunque con menor vertiginosidad. Además, en estos mismos años la provincia impulsaba un programa desarrollista, concentrado en las zonas de la cordillera y la costa, a través de la generación de polos industriales que tendieron a atraer a esta población rural disponible. Se estimuló así la migración, sobre todo de los miembros más jóvenes de las familias cuyos campos no rendían para sostener a todos sus integrantes.

Los procesos poblacionales recién señalados también estuvieron determinados por el objetivo de mejorar la calidad de vida. La cercanía con instituciones de salud y educativas fue determinante para las estrategias residenciales de muchas familias (Hermosilla Rivera, 2013). Según la encuesta a hogares realizada en 2016, y ante la pregunta por los motivos de asentamiento, la cercanía a un establecimiento educativo ocupa el tercer lugar en importancia, luego de los motivos laborales y de acceso a la vivienda (Crovetto y Di Paolo, 2019). En consonancia con estos datos, en entrevistas realizadas a residentes de poblados mesetenses se constata el deseo de acompañar a sus hijas e hijos en su tránsito escolar.

En adición, la experiencia propia de haber pasado por una escuela de tipo internado se destaca como una de las razones para evitarles a sus hijas e hijos el mismo tipo de educación. Se trata de aquello que Lahire (2004) entiende como múltiples pliegues de socialización que se actualizan en un determinado contexto, en este caso el de la maternidad/paternidad.

\footnotetext{
-Entrevistadora: ¿Vos y tus hermanos concurrieron a escuela internado?

-Entrevistada: Yo estuve un poco más que mis hermanos.

-Entrevistadora: ¿Por qué?

-Entrevistada: Y, mis hermanos...porque ya cuando yo salí de la escuela trabajé y tuve mi casa acá y ya se quedaban conmigo, en esa época había mucho maltrato (exalumna de internado, Paso de Indios, septiembre 2016)
}

-Entrevistada: No, no los mandaría (...) pasan cosas que a veces no salen a la luz...Entonces...pudiendo...buscamos la forma de estar cerca (madre con hijos en edad escolar, Cushamen, septiembre 2016)

En este mismo período las escuelas internado dejan de existir para reconvertirse en albergues: un cambio que no fue sólo nominal, sino también de forma. Los abusos denunciados durante el funcionamiento de los internados establecieron la necesidad de rever la periodicidad con la que el alumnado visitaba a su familia. ${ }^{19}$ Se buscó así revertir la separación familiar y comunitaria implícita en la creación de esta modalidad. Los albergues dan hogar sólo de lunes a viernes, mientras que los fines de semana las familias deben hacerse cargo de las alumnas y los alumnos. Debido a que muchas veces la distancia hizo imposible esta asiduidad, surgieron 
las figuras de tutores y tutoras (mayormente familiares, amigos o exvecinos residentes en las cercanías de las escuelas). Encontrar estas familias cuidadoras de fin de semana no fue un conflicto para el funcionamiento de los albergues dado que, como ya se mencionó, había habido una importante migración de mesetenses hacia otras zonas de la provincia.

\section{EDUCACIÓN COMO DERECHO}

En el período actual, la población de la MCCh es de 5716 habitantes (CNPHyV 2010); si bien su despoblamiento ha disminuido, es un proceso que continúa, aunque de forma más gradual.

Respecto de las modalidades escolares ofertadas, y en estrecha relación con la concentración de la población mesetense, la mayoría de las niñas y los niños en edad escolar estudian en instituciones cercanas a sus casas. Para el nivel primario, el funcionamiento escolar es similar al de los contextos urbanizados: jornadas simples o completas, luego de las cuales se retorna al hogar familiar. La educación del nivel medio se ha expandido bajo la modalidad de Nueva Secundaria Rural, cuyos principales ejes se fundamentan en la Ley Nacional de Educación (LEN), sancionada en el 2006. La LEN, al establecer la educación como un derecho individual y social, hizo responsable al Estado de facilitar el acceso educativo con criterios de igualdad, integralidad y equidad para el ejercicio de una ciudadanía democrática. En este marco, se sancionó por primera vez la modalidad rural como transversal a todo el sistema. Bajo la impronta de evitar el desarraigo, el artículo 50 establece que se deben "Promover diseños institucionales que permitan a los/as alumnos/as mantener los vínculos con su núcleo familiar y su medio local de pertenencia durante el proceso educativo”.

Además, se extendió la escolaridad respecto de lo establecido por la Ley Federal de Educación (No24195/94), de 10 a 12 años, con lo que se sancionó como obligatoria la educación del nivel secundario.

La Nueva Escuela Rural, establecida en 2015 con el decreto provincial $n^{\circ} 22$, se organiza con docentes disciplinares que dictan clase cada 15 días, apoyados por docentes tutores que se encargan del curso entre esos períodos. Sin embargo, según las entrevistas realizadas, la calidad educativa de este formato es considerada como baja en relación con las de modalidad común, de tipo urbanas; el funcionamiento, incluso, muchas veces se ve dificultado por la ausencia de docentes de ciertas disciplinas como matemáticas, quienes son suplantados por otros profesores disponibles para el nivel.

Pero bueno, quiso ir allá [Residencia estudiantil] porque quizás la escuela rural no es tan buena. Yo lo comprobé con todos mis hijos: él hizo hasta 6to nomás, los demás hasta 9no y después se fueron a Trevelin a la Agrotécnica. Estudiaron allá pero les costó mucho. (Entrevista a madre de 5 hijos que asistieron a escuelas albergue y residencias escolares; El Maitén, octubre 2019)

Yo, por ejemplo, intenté traer chicos del interior, en este caso de Los Altares, para que rindieran un examen de ingreso en la politécnica de Rawson y les fue mal. Les fue mal porque no tienen el mismo nivel en la secundaria rural que los que se preparan acá para entrar. Entonces los chiquitos quedaron, uno solo quedó acá, otro se volvió porque él quería ir a la politécnica. Ir a la poli, viste. Pero ya son otras cuestiones.(Entrevista a directora de Casa estudiantil de Playa Unión; Playa Unión, agosto 2019)

Respecto de las escuelas albergue, han pasado a denominarse Casas y Residencias Estudiantiles. Este cambio de modalidad permite que el alumnado de nivel secundario pueda asistir a escuelas que no necesariamente son las contiguas a la casa o residencia donde viven. Además, se ha establecido la figura de "re-vinculación familiar", lo que hace que las y los estudiantes tengan un vínculo más continuo con sus familias y contextos de residencia. Dado que se ha expandido la oferta escolar en los poblados mesetenses, y que la población agrupada es cada vez más mayoritaria, la matrícula de estas instituciones ha disminuido significativamente, por lo que se encuentran en un proceso de reconversión que acoge también a estudiantes de nivel terciario. Por lo general, las familias que eligen estas instituciones apuestan a la continuidad educativa de sus hijos/as, alentando un futuro relacionado con la migración hacia contextos urbanizados y entendiendo que esta modalidad ofrece 
la mejor formación para todo ello. En la actualidad, la matrícula provincial de estas instituciones es de 392 estudiantes de todos los niveles del sistema educativo.

\section{CUADRO 1}

Períodos de la relación entre las modalidades educativas ofertadas en la MCCh y las dinámicas residenciales de su población

\begin{tabular}{|c|c|c|c|}
\hline Período & $\begin{array}{l}\text { Modalidades } \\
\text { educativas } \\
\text { ofertadas }\end{array}$ & $\begin{array}{l}\text { Dinámicas } \\
\text { poblacionales }\end{array}$ & Relación \\
\hline \multirow[t]{3}{*}{ Nacionalización } & $\begin{array}{l}\text { Escuelas } \\
\text { ambulantes }\end{array}$ & Repoblamiento & \multirow{3}{*}{$\begin{array}{l}\text { Debido a los objetivos civilizatorio, y } \\
\text { teniendo en cuenta la dispersión } \\
\text { poblacional, se idean y concretizan las } \\
\text { modalidades escolares. } \\
\text { Escuelas internado: separan al } \\
\text { estudiantado de su familia y comunidad. } \\
\text { Las Aldeas Escolares asientan población } \\
\text { bajo cierto orden. }\end{array}$} \\
\hline & $\begin{array}{l}\text { escuelas } \\
\text { internado. }\end{array}$ & \multirow[t]{2}{*}{$\begin{array}{l}\text { Ordenamiento } \\
\text { poblacional }\end{array}$} & \\
\hline & $\begin{array}{l}\text { Aldeas } \\
\text { escolares }\end{array}$ & & \\
\hline \multirow{2}{*}{$\begin{array}{l}\text { Crisis de la } \\
\text { producción } \\
\text { ovino-lanar }\end{array}$} & $\begin{array}{l}\text { Escuelas en los } \\
\text { pueblos }\end{array}$ & Despoblamiento & \multirow{2}{*}{$\begin{array}{l}\text { Mayor concentración, que estimula la } \\
\text { expansión escolar. Escuelas que atraen } \\
\text { familias hacia el nucleamiento poblacional. } \\
\text { Para la restante población dispersa: } \\
\text { escuelas albergue, que buscan disminuir el } \\
\text { desarraigo. }\end{array}$} \\
\hline & $\begin{array}{l}\text { Albergues } \\
\text { escolares }\end{array}$ & Concentración & \\
\hline \multirow[t]{3}{*}{$\begin{array}{l}\text { Educación como } \\
\text { derecho }\end{array}$} & $\begin{array}{l}\text { Escuelas en los } \\
\text { pueblos }\end{array}$ & \multirow[t]{3}{*}{ Concentración } & \multirow{3}{*}{$\begin{array}{l}\text { Renovadas concepciones respecto de la } \\
\text { educación en general, y rural en particular, } \\
\text { y sus deberes. Nuevas modalidades } \\
\text { impulsadas a garantizar el derecho a la } \\
\text { educación, sorteando la dificultad de } \\
\text { garantizar la presencia de profesores para } \\
\text { el nivel medio. } \\
\text { Proceso de inclusión excluyente: hacia } \\
\text { adentro del sistema. }\end{array}$} \\
\hline & $\begin{array}{l}\text { Nueva } \\
\text { Secundaria } \\
\text { Rural }\end{array}$ & & \\
\hline & $\begin{array}{ll}\text { Casas } & \text { y } \\
\text { Residencias } & \\
\text { estudiantiles } & \end{array}$ & & \\
\hline
\end{tabular}

Fuente: Elaboración propia

\section{CONSIDERACIONES FINALES}

El objetivo de este trabajo ha sido exponer los roles cumplidos por la institución escolar, en sus diferentes modalidades, en las dinámicas migratorias y de residencia de la población de la MCCh. Esta relación no ha sido lineal en términos de causa-consecuencia, sino que se ha dado como un proceso en el que ambas partes se estimulan mutuamente. Así, durante el período de ovinización-nacionalización-territorialización de la MCCh, garantizar estatalmente el orden del repoblamiento estuvo ligado estrechamente con la búsqueda de escolarizar a esta población; un proceso de imposición simbólica, de establecimiento de un arbitrario cultural dentro de otras múltiples posibilidades (Bourdieu y Passeron, 1996). Al mismo tiempo, la organización escolar debía adaptarse a la dispersión de los habitantes mesetenses, así como hacer frente a las resistencias familiares para adoptar la escuela entre sus estrategias. Tales fueron los casos de las instituciones ambulantes; y luego las de tipo internado, cuya propuesta se basó en separar a las y los estudiantes de sus familias y comunidades. Las Aldeas Escolares representaron la forma más acabada del esfuerzo del Estado nacional por organizar, bajo ciertas reglas y valores, la vida de la población mesetense en torno a una institución educativa.

Con la crisis de la producción ovino-lanar, muchos productores abandonaron sus campos y se vieron expulsados hacia otras regiones de la provincia en búsqueda de trabajo. Asimismo, otro porcentaje de la población tendió a agruparse. Esta concentración estimuló la instalación de nuevas escuelas; pero al mismo 
tiempo -y en un proceso inverso- estas instituciones atrajeron familias, o partes de estas (madres e hijos/as), a instalarse en los poblados. Tal como sostiene Hermosilla Rivera (2013), la contención social que brinda la cercanía a los servicios de salud y educación es la principal causa del aumento poblacional de las localidades rurales en la meseta. Como se ha señalado, esta necesidad familiar de acompañar a sus miembros más jóvenes durante el trascurso escolar tiene que ver con socializaciones propias en escuelas internado, que no desean para sus hijos/as. Esta nueva relación de las familias con la escuela, y respecto de su rol en el acompañamiento de las y los estudiantes, puede comprenderse como una creciente valorización positiva de aquellas hacia la formación escolar. Además, la propuesta estatal también tuvo modificaciones. Fruto de estas experiencias de desarraigo y malos tratos, y de las tendencias de despoblamiento de la zona, las escuelas internado pasaron a ser albergues, con un nuevo funcionamiento en el que las familias y sus redes sociales estuvieron más involucradas.

En el período actual, las modalidades escolares ofertadas buscan respetar lo sancionado por la LEN, adaptándose a las costumbres y posibilidades locales en pos de garantizar un vínculo más estrecho entre las y los estudiantes, sus familias y su contexto de residencia. Lo hacen bajo una óptica relacionada con la educación entendida como derecho, en oposición a la imposición simbólica que guio las acciones del Estado durante el período de nacionalización. Sin embargo, al igual que cien años antes, sigue siendo un desafío, en estos contextos ruralizados y aislados, garantizar la escolarización de calidad para el nivel medio. Si bien las ofertas tienden a incluir cada vez más población, se dan distintas formas de inclusión ahora hacia adentro del sistema, diferenciando tipos de ofertas y calidades escolares (Nobile, 2016) según los capitales con los que cuentan las familias.

\section{REFERENCIAS}

Aparicio, S., Crovetto, M. y Ejarque, M. (2013). Las condiciones de trabajo de los asalariados en la esquila patagónica argentina. Mundo Agrario, 13. Recuperado de https://www.mundoagrario.unlp.edu.

Bourdieu, P. (1994). Las estrategias de la reproducción social. Buenos Aires: Siglo XXI.

Bourdieu, P. y Passeron, J. (1996). La Reproducción: elementos para una teoría del sistema educativo. México: Fontamara.

Carabelli, F., Demarchi, G. yBaroli, C. (2008). Desarrollo local de la Comarca de la Meseta Central de Chubut. En Emprendedores de la Economía Social (pp. 109-140). Buenos Aires: Editorial Ciccus.

Cárcano, R. (1933). 800.000 Analfabetos. Aldeas escolares. Buenos Aires: ROLDAN EDITOR.

Caviglia, S. (2011). La Educación en el Chubut 1810-1916. Rawson: Ministerio de Educación de la Provincia de Chubut.

Crovetto, M. y Di Paolo, M. (2019). Territorios atravesados por la movilidad espacial: migraciones, comunicación y educación como transformadoras de los horizontes de expectativas en la Patagonia argentina. Temas de Antropología y Migración, 11, 86-99. Recuperado de http://www.migrantropologia.com.ar/images/stories/PD F/Revista11/revista_migrantro11.pdf

Duarte, D. (2015). Al sur de la frontera. Las escuelas en la Patagonia a fines del siglo XIX. Revista de Estudios Marítimos y Sociales, $7 / 8,192-214$.

Ejarque, M. (2014). Reconstruyendo la historia ambiental de las tierras secas chubutenses (Argentina). Zonas Áridas, 15(1), 169-187.

Franco, D. (2003). Espacios de representación e imaginario social en aldeas escolares de la provincia de Chubut. Párrafos geográficos, 2(2), 31-40.

Giberti, H. (1962). El Desarrollo Agropecuario. Desarrollo Económico, 2(1), 65-126. Recuperado de http://www.jst or.org/stable/3465699.

Haesbaert, R. (2013). Del mito de la desterritorialización a la multiterritorialidad. Cultura y representaciones sociales, $8(15), 9-42$. 
Hermosilla Rivera, H. (2013). Población rural en Chubut: la meseta desde principio de siglo xx a la actualidad. Párrafos Geográficos, 12(1), 32-75.

Lahire, B. (2004). El hombre plural: Los resortes de la acción. Barcelona: Edicions Bellaterra. Traducción de M. J. Devillard.

Morales Zuñiga, L. (2009). Durkheim y Bourdieu: reflexiones sobre educación. Revista Reflexiones, 88, 155-162.

Nobile, M. (2016). La escuela secundaria obligatoria en Argentina: desafíos pendientes para la integración de todos los jóvenes. Última Década, 44, 109-131.

Pierini, M. y Rotman, S. (2009). La escuela como presencia del Estado Central en el Territorio Nacional de Santa Cruz. XII Jornadas Interescuelas/Departamentos de Historia. Departamento de Historia, Facultad de Humanidades y Centro Regional Universitario Bariloche. 28 al 31 de octubre de 2009. Universidad Nacional del Comahue, San Carlos de Bariloche.

Sack, R. (1986). Human Territoriality: its theory and history. Cambridge: Cambridge University Press.

Taraborelli, D. (2019). Ovejas al sur. Caracterización del sector lanero chubutense desde la economía política. Revista RIA - INTA, 1, 359-372.

Troncoso, A. (2008). La experiencia del magisterio en la meseta chubutense (1930-1970). En $3^{\circ}$ Jornadas de Historia de la Patagonia, Universidad Nacional de Río Negro, Bariloche, Argentina. Recuperado de http://www.hechoh istorico.com.ar/Trabajos/Jornadas\%20de\%20Bariloche\%20-\%202008/Troncoso.pdf.

Troncoso, A. y Flores Torres, M. (2012). Las relaciones sociales en la Meseta Norte de Chubut (1930-1970). Un abordaje desde la perspectiva poscolonial. Tabula Rasa, 17, 131-149.

\section{Notas}

1 Melisa Di Paolo. Profesora y Licenciada en Ciencias de la Comunicación (UBA). Becaria doctoral CONICET con sede en el Área de Estudios Rurales del Instituto de Investigaciones Gino Germani. Sus temas de trabajo son las estrategias educativas de familias residentes en contextos ruralizados, más específicamente en la Meseta Central de Chubut.

2 Entenderemos aquí por escuela todas aquellas instituciones estatales y públicas dedicadas a la educación formal, independientemente de su modalidad o nivel; éstos serán oportunamente señalados a los fines argumentativos de esta exposición.

3 Este artículo es resultado del proceso de tesis de maestría de la autora, titulada "Estrategias educativas familiares y ofertas disponibles: un estudio diacrónico de su juego en la Meseta Central de Chubut”, para optar al título de Magíster en Investigación en Ciencias Sociales de la Facultad de Ciencias Sociales, UBA.

4 La Ley de Educación Común fue sancionada durante la presidencia de Julio A. Roca tras arduas discusiones dentro del $\mathrm{CNE}$, que fueron expuestas en el Congreso Pedagógico Internacional de 1882. Esta ley dispuso la instrucción primaria como obligatoria, gratuita y gradual. Ello suponía que la escuela primaria pública debía estar al alcance de toda la población.

5 Si bien esta modalidad será descripta con mayor profundidad más adelante, consta de hogares contiguos a las escuelas, donde el alumnado transcurre el tiempo extra-escolar al cuidado de un grupo de asistentes infantiles.

6 Se trató de entrevistas semi-estructuradas, tanto individuales como grupales, llevadas a cabo en diversas localidades de la Meseta (Gualjaina, Paso de Indios, Cushamen, Gastre, Paso del Sapo y Maitén), así como en las ciudades de Rawson, Trelew y Playa Unión, en septiembre de 2016, y agosto y octubre de 2019 [¿Habría que poner "respectivamente”?]. El corpus estuvo conformado por 24 entrevistas totales realizadas con: ex y actuales alumnos y alumnas de escuelas internado, albergue y de Casas y Residencias estudiantiles (I,A,C,R); padres y madres con hijos e hijas asistentes a escuelas I,A,C,R ; docentes y asistentes infanto-juveniles de las modalidades I,A,C,R; directores anteriores y actuales de este tipo de escuelas; anteriores y actuales funcionarios/as de la modalidad rural de la provincia del Chubut, así como otros funcionarios/as estatales vinculados en su labor profesional con la población mesetense.

7 Muchas de las reflexiones que aquí se expondrán son el resultado del análisis de un operativo colectivo de encuestas a hogares en la Meseta Central de Chubut, llevado a cabo por el Equipo de estudios de mercados de trabajo agropecuarios, perteneciente al Área Rural de Instituto de Investigaciones Gino Germani, UBA. Este relevamiento tuvo lugar en septiembre de 2016; se llevó a cabo en las localidades mesetenses de Paso de Indios, Gualjaina, Cushamen, Gan Gan, Telsen, Las Plumas, Paso del Sapo, Los Altares y Dique Ameghino; y fue financiado por el proyecto ANPCYTFONCYT (PICT 2013-0224). 
8 Según registra el INDEC, se considera rural a toda aquella aglomeración poblacional con menos de 2000 habitantes. Mientras la población rural agrupada es la que habita en estos nucleamientos rurales, la dispersa está conformada por las personas que residen en campo abierto, sin constituir centros poblados.

9 La MCCh está organizada en dos municipios de segunda categoría (Paso de Indios y Gualjaina); once comunas rurales (Aldea Epulef, Colan Conhue Cushamen, Dique Florentino Ameghino, Gan Gan, Gastre, Lagunita Salada, Las Plumas, Los Altares, Paso del Sapo y Telsen); cincuenta parajes (como Blancuntre, El Mirasol, Chacay Oeste y Yala Laubat, entre otros) y demás campos dispersos.

10 Fuente: Sistema Estadístico Provincial de Chubut. Recuperado de http://www.estadistica.chubut.gov.ar, con fecha en 18/08/2018.

11 Subsecretaría de Planificación Territorial de la Inversión Pública. Recuperado de http://www.argentina.gob.ar/plan_e strategico_de_infraestructura_de_chubut el 20/10/2019.

12 Cálculo de elaboración propia según los datos del Censo Nacional de Población del año 2010 (INDEC, Dirección General de Estadísticas y Censos de Chubut).

13 Esta modalidad será analizada con mayor profundidad en el apartado "La educación como derecho".

14 En la actualidad, la provincia cuenta con tres Casas estudiantiles, emplazadas en Esquel, Sarmiento y Playa Unión (Rawson). Esta última es la formalmente destinada a la población mesetense.

15 Hay 22 Residencias en toda la provincia, que se localizan en Fofo Cahuel, Colonia Cushamen, El Turbio, El Maitén, Cushamen Centro, Cholila, Carreleufú, Tecka, Paso del Sapo, Costa del Chubut, Piedra Parada, Costa del Lepá, Trevelin, Tecka, Gobernador Costa, Camarones, El Escorial, Blancutre, Chacay Oeste, Gastre y Río Mayo.

16 Término al que aluden Troncoso y Flores Torres (2012) para referirse a la expansión de la producción ovino-lanar en la MCCh, como proceso que estableció una configuración desigual entre la población, bajo la dirección del Estado y el Mercado.

17 Este organismo fue creado en 1881, un año después de la federalización de Buenos Aires, y tuvo por objetivo gobernar y administrar sus escuelas primarias públicas. Con la Ley de Educación Común (Ley 1420/1884) pasan a su cargo las escuelas de Capital, Colonias y Territorios. En 1905, con la Ley Láinez, sus competencias se ampliaron a las provincias mediante la creación de escuelas primarias. Recuperado de http://www.argentina.gob.ar/educacion.

18 Benjamín Zorrilla, presidente del Consejo Nacional de Educación entre 1882 y 1895.

19 Respecto de este proceso, según el exdirector de escuelas primarias del Chubut, en el año 1989, de los sumarios a cargo de la Dirección de Asuntos Jurídicos el 50\% pertenecía a las 25 escuelas de tipo internado, mientras el otro 50\% se repartía entre las 110 instituciones primarias comunes (entrevista a exdirector de escuelas primarias de la provincia de Chubut, Trelew, agosto 2019). 